\title{
Intercultural Relationship, Prejudice and Ethnocentrism in a Computer-Mediated Communication (CMC): A Time-Series Experiment
}

\author{
Hasrina Mustafa, Ph.D. (Corresponding author) \\ School of Communication, Universiti Sains Malaysia, 11800 Penang, Malaysia \\ Tel: 60-19-322-8232 E-mail: hasrina@usm.my \\ Hamidah A. Hamid \\ School of Communication, Universiti Sains Malaysia, 11800 Penang, Malaysia \\ Tel: 60-4-653-3603 E-mail: hamidah@usm.my \\ Jamilah Ahmad, Ph.D. \\ School of Communication, Universiti Sains Malaysia, 11800 Penang, Malaysia \\ Tel: 60-4-653-3603 E-mail: jahmad@usm.my \\ Kamaliah Siarap \\ School of Communication, Universiti Sains Malaysia, 11800 Penang, Malaysia \\ Tel: 60-4-653-3603 E-mail: kamaliah@usm.my
}

Received: September 21, $2011 \quad$ Accepted: October 24, $2011 \quad$ Published: March 1, 2012

doi:10.5539/ass.v8n3p34

URL: http://dx.doi.org/10.5539/ass.v8n3p34

The research is financed by the Ministry of Higher Education Malaysia No. 203/PCOMM/671125(FRGS)

\begin{abstract}
This paper investigated the effects of relationship types (intracultural versus intercultural conditions) on relational development in computer-mediated communications (CMC) and face-to-face settings by controlling for the effect of prejudice and ethnocentrism. A total of 140 participants were involved in the experiment, and they were randomly assigned to the face-to-face, synchronous and asynchronous computer-mediated channels. Within each group, they were assigned to intracultural versus intercultural conditions and were required to interact in pairs with their zero-history partners. All participants underwent four experimental sessions.. The results exhibited a significant main effect of relationship types on relational progression in face-to-face and asynchronous CMC groups. No significant main effect of relationship types was observed in the synchronous CMC group. The results showed no significant effects of prejudice and ethnocentrism on relational development in all groups. The findings of the study provide partial support for the "equalization" view of CMC.
\end{abstract}

Keywords: Intercultural relationship, Equalization, Computer-Mediated Communication (CMC), Prejudice, Ethnocentrism

\section{Introduction}

The proliferation of the Internet has tremendously changed the communication landscape by allowing individuals from different cultural backgrounds and ethnicities in various parts of the world to communicate with each other quickly and directly. For intercultural communication scholars, online communication technology has brought a new dimension to the study of intercultural communication. It provides a new testing ground for intercultural communication theories, which previously were limited to face-to-face interactions. For new media researchers, 
online technology offers an exciting research platform to test new CMC theories on existing issues, such as intercultural relations. The best way to begin is to compare the existing literature on intercultural communication in face-to-face communication and CMC, described in the following sections.

\section{Literature Review}

\subsection{Intercultural Relationships in Face-to-Face Setting}

Past research has concluded that intercultural communication is different from intracultural communication (Stanback \& Pearce,1981; Simard, 1981; Turner \& Giles; 1981). According to Gudykunst (1986), previous analyses suggested there are significant differences between intracultural communication (communication with people of the same culture) and intercultural communication (communication with people of a different culture). In one study of 326 students (163 whites and 163 African-Americans), Gudykunst (1986) reported that there are significant differences in intracultural and intercultural self-disclosure, perceived similarity and attributional confidence. Most students in the study associated their intracultural relationship with greater self-disclosure, perceived similarity and attributional confidence.

Theoretical frameworks were developed from these empirical findings. According to Neuliep (2003), whenever we communicate with someone from a different culture, we experience much uncertainty. We may not know anything about a person's culture, values, habits, behavior, dress or other factors. Berger (1988) further theorizes that when we interact with a stranger (especially a person from a different culture), our primary concern is to reduce uncertainty. In this high uncertainty situation, our primary goal is to reduce uncertainty and increase the predictability about the other. This can be accomplished through specific verbal and nonverbal communication strategies, such as question asking and appropriate nonverbal expressiveness.

Gudykunst and Kim (1997) argue that whenever we interact with people from different cultures, we tend to view them as strangers. Interactions with people from different cultures tend to involve the highest degree of strangeness and the lowest degree of familiarity. There is greater uncertainty in initial interactions with strangers than with people with whom we are familiar. Interaction with people of a different culture often leads to anxiety.

According to Neuliep (2003), intercultural communication is a complex combination of the cultural, multicultural, environmental, perceptual and socio-relational contexts between two people who are encoding and decoding verbal and nonverbal messages. Whenever people from different cultures met and exchange messages, people bring a host of thoughts, values, emotions and behaviors planted and cultivated by their cultures.

Despite complexities in intercultural interaction that can hinder positive relational development, Allport's (1954) Intergroup Contact Theory specified four criteria necessary for a positive intercultural interaction: 1) the partners should be of equal status; 2) the contact must be supported by authorities; 3 ) the contact should be in pursuit of common goals; and 4) the contact must be cooperative in nature. These facilitating conditions have been studied extensively, and studies have showed that contacts meeting these conditions are more effective in shaping attitudes than contacts that do not (Harwood, 2010).

Although the four facilitating conditions appear promising and achievable, the reality is more challenging. Increasing intercultural contact in intercultural situations in countries, such as India, Malaysia and Indonesia, has had more negative effects and imposed a more negative perception. According to Varney and Cushner (1990), intercultural contact may lead to further misunderstanding due to incorrect interpretation of cues among the communicating partners from different cultures. According to Amichai-Hamburger and McKenna (2006), intergroup communication in a face-to-face setting can be problematic due to physical, language and contextual differences, which can highlight status differences. Allport (1954) also noted that intercultural contact could reinforce stereotypes and negative attitudes among participants. Clearly, increasing intercultural contact and proximity do not guarantee positive intercultural exchanges or a more intercultural relationship.

Based on the above, we assume a greater development of interpersonal relationships among intracultural communicative partners when compared to the intercultural communicative partners in face-to-face groups. In other words, the effect of relationship types (intracultural versus intercultural) on relationship progression would be significant in face-to-face groups. Based on this argument, the following hypothesis is offered.

H1: The effects of relationship types (intracultural and intercultural) on the development of interpersonal relationships are significant in the face-to-face group.

\subsection{Intercultural Relationships in CMC}

Various studies have examined relational development in CMC (Walther \& Burgoon, 1992; Walther, 1994; Chidambaram, 1996; Utz, 2000). A pessimistic view is that CMC produces different affective and relational 
patterns than other types of communication, such as face-to-face, due to reduction of cues available to participants (Hiltz, Johnson \& Turoff, 1986; Rice \& Love, 1987, Daft \& Lengel, 1984). As a result, interaction through CMC is considered impersonal and more task-oriented than face-to-face communication. There are several theories based on this perspective, namely, the cues filtered out, media richness and social presence theories.

Recent developments and research findings, however, have led to a more promising view of online relationships. Walther and Burgoon (1992) proposed the Social Information Processing (SIP) theory, which predicts that the dimensions of interpersonal relationships in CMC groups would develop and progress positively over time and that this progression would approximate the level of a face-to-face group. Walther (1996) further introduced the "hyperpersonal" effect of CMC, which holds that CMC partners may develop a greater level of immediacy than the face-to-face partners. This model was an extension to the SIP theory, and it was developed to account for the extraordinary depth and intimacy sometimes associated with CMC interactions. Walther (2009) further highlights that recent $\mathrm{CMC}$ research has empirically concluded the positive impact on online interaction against the earlier pessimistic effect view of CMC.

Although research on online relationships is accumulating because of the unprecedented pace of significant empirical findings, we observed that a limited number of studies focused on online relational development among people of different cultures. In fact, according to Ma (1996), mediated intercultural relations have been addressed only in a few unpublished studies, and Yum and Hara (2006: pg. 133) added, "little is yet known about how people utilize CMC as a relational communication channel in different cultures."

Intercultural communication in the face-to-face setting is challenging due to various physical, contextual and perceptual barriers. How does the situation compare for the online medium? The SIP and the hyperpersonal perspectives address the promising effect of $\mathrm{CMC}$ in online relationship development, without taking into consideration the effect of culture. Will the assumptions of the SIP theory and hyperpersonal perspectives hold in different cultures?

To answer this question, we explore a related perspective in CMC. This perspective is known as "the equalization view" of CMC (Rodino, 1997). The equalization view holds that CMC democratizes communication due to the reduction of social cues in the media. According to Rodino (1997), computers were touted for their democratizing potential. Because CMC reduces social cues, such as physical appearance, gender and race, it democratizes communication.

Empirical evidence for theoretical understanding is widely documented. Bordia (1997), in a meta-analysis of 18 published experimental research articles comparing face-to-face and $\mathrm{CMC}$, reported that there was greater equality of participants in CMC groups when compared to the face-to-face groups. McGuire, Kiesler and Siegel (1987) and Siegel, Dubrovsky, Kiesler and McGuire (1986) reported that in CMC groups, participation tends to be more balanced and equitable. Fewer barriers and greater equality have been associated with computer-mediated interaction than with face-to-face interaction because of the medium's lack of visual and social cues ( Van Gelder, 1991). Walther (1992) further concluded that the tendency for an individual or a faction of a group to dominate group discussions dissipated in the computer-mediated interaction.

The reason underlying this theoretical view is clear. In CMC, communicators are connected through the computer, which inevitably eliminates the direct physical interaction and feedback available in face-to-face communication. No visual cues (such as physical appearance, gender and race), nonverbal cues or social context cues (physical adornment and room setting), which characterize status, are available. The lack of these social cues and barriers equalize participation. When such cues are absent, the actors become disinhibited when they would otherwise defer to higher status participants (Walther \& Burgoon, 1992).

Siegel, Dubrovsky, Kiesler and McGuire (1986) further added that CMC democratizes communication among people by allowing the communicators to become disinhibited from social bounds and barriers and explore true freedom of expression. Van Gelder (1991) also holds the same opinion because according to him, some barriers common to face-to-face communication, such as race, gender, physical appearance and language accent, are nonexistent in $\mathrm{CMC}$, creating a more egalitarian situation. The most important criterion by which we judge each other in CMC is one's mind rather than appearance, race, gender or accent.

We observe the same potential of a positive intercultural encounter in the online medium in intergroup contact theory (1954). The four criteria, equal status, institutional support, common goals and cooperative nature, are feasible to achieve in $\mathrm{CMC}$ and may lead to more positive intercultural relations among online participants. Walther (2009) similarly noted that research on offline intergroup contact has discovered a variety of conditions that help facilitate interethnic relations, many of which CMC help to meet. Amichai-Hambuger and McKenna 
(2006) proposed that online interaction has greater advantages than face-to-face interaction in building positive contact among people.

Mustafa and Hassan (2006), in one longitudinal quasi-experiment, found no significant difference in the development of interpersonal relationships among intracultural and intercultural partners in CMC. Both intracultural and intercultural partners showed a comparable rate of relational progression. Ma (1996) examined intercultural communication in CMC among East Asian and North American college students and reported that both East Asians and North Americans perceive computer-mediated intercultural communication as a more egalitarian experience than face-to-face intercultural communication. Both cultural groups acknowledged that status differences were unnoticeable in computer-mediated conversations.

Because the common barriers in intercultural face-to-face interaction, accent and physical appearance, are non-existent in CMC (Ma, 1996), an equal interaction occurs, which can lead to an equal rate of relational development among intracultural and intercultural communicative partners. Cross-cultural partners in CMC would also feel less anxiety than cross-cultural partners in a face-to-face setting.

Based on this argument, we can predict that there should be no differences among intracultural communicative partners or intercultural communicative partners on the development of interpersonal relationships in CMC. Both intracultural and intercultural communicative partners should develop relationships at almost the same pace. We proposed the following hypothesis:

$\mathrm{H} 2$ : The effect of relationship types (intracultural versus intercultural) is not significant in the development of interpersonal relationship in the CMC groups.

\subsection{Prejudice, Ethnocentrism and Relational Development}

Despite a vast amount of literature on CMC, little is known about the effect of perceptual barriers, especially prejudice and ethnocentrism on intercultural relationships in CMC. In fact, much literature on prejudice and ethnocentrism was derived from intercultural studies in a face-to-face setting. Gudykunst (1986) noted each time we interact with people from a different culture, we bring a perceptual frame of reference that filters all our messages (Neuliep, 2003). Two important perceptual frames of reference influencing intercultural communication are prejudice and ethnocentrism.

Prejudice consists of negative attitudes toward social groups (Stephan, 1985). According to Stephan, Ageyev, Coates-Shrider, Stephan and Abalakina (1994), prejudice may consist of cognitive, affective and behavioral components. Prejudice involves members of one group attributing characteristics to members of another group. These attributions typically carry a positive and negative evaluation.

According to Neuliep (2003), ethnocentrism refers to the idea that one's own culture is at the center of everything, and all others are scaled and rated with reference to it. Ethnocentrism nourishes a group's pride and vanity and looks on outsiders or out-groups with contempt.

Toal and McCroskey (2001) found that ethnocentrism is positively related to apprehension about, and negatively related to, the use of relational maintenance strategies in interethnic relationship. Goldstein and Kim (2005) similarly found that high levels of ethnocentrism and prejudice are negatively related to the intention to participate in study abroad programs. Dovidio, Esses, Beach and Gaertner (2002) highlighted the relationship between prejudice and levels of apprehension in intercultural interaction.

Barna (1999) further identified preconceptions, such as prejudice, as one of the major stumbling blocks in face-to-face intercultural communication. The prejudgemental perceptions may have a substantial effect on the development of online relationships, especially during initial encounters. According to Gudykunst (1986), once relationships between people of different ethnic groups reach the friendship stage, there may be little difference between these relationships and those between people of the same ethnic group. Neuliep (2003) further noted that cross-cultural partners may face a large amount of uncertainty and anxiety during initial encounters, but as they learn more about each other, their relationships develop positively.

Altman and Taylor (1973) asserted that perceptual barriers are broken down in intimate relationships. Thus, prejudice and ethnocentrism may affect relational development during initial encounters, but they later diminish over time, as partners shared and disclosed more personal information in CMC.

In light of various empirical findings in the existing cross-cultural communication face-to-face literature on the effect of both perceptual barriers on intercultural exchanges, we predict a strong correlation among prejudice, ethnocentrism and interpersonal relationships. We also predict that the level of prejudice and ethnocentrism would decrease as the relationship progresses. Prejudice and ethnocentrism work in a direction opposite to 
relational progression, meaning that as a relationship progresses, the level of ethnocentrism and prejudice will start to flatten. In other words, prejudice and ethnocentrism will be negatively correlated with relational development in all channels, especially in face-to-face settings.

The question now is how salient are prejudice and ethnocentrism in online relationship development? Earlier, we predicted an equal rate of relational development among intracultural and intercultural communicative partners in the CMC groups, as the barriers in intercultural face-to-face interaction, such as accent and physical appearance, are non-existent in CMC. However, we must remember that even though physical appearance is not apparent in $\mathrm{CMC}$, one often has prejudgmental perceptions, such as prejudice and ethnocentrism, before the actual encounter, having a substantial effect on the development of online relationships with people of a different culture. The existence of prejudice and ethnocentrism, therefore, could frustrate harmonious and close intercultural relations in CMC. Due to a lack of cross-cultural research in CMC, particularly related to the effect of prejudice and ethnocentrism on relational progression in $\mathrm{CMC}$, we posed the following research question:

RQ1. What is the effect of prejudice and ethnocentrism on the development of intracultural versus intercultural partners in face-to-face, synchronous CMC and asynchronous CMC groups?

\section{Methodology}

\subsection{Experimental Procedures}

The study used a longitudinal experimental design to achieve the objectives of the study. We used a three groups repeated measures design (Campbell \& Stanley, 1963), which involved repeated measurement of the dependent variable over time on three groups (face-to-face, synchronous $\mathrm{CMC}$ and asynchronous $\mathrm{CMC}$ ), representing levels of the independent variable.

Subjects in the face-to-face control group had to attend four sessions conducted once a week over a four-week period. They were placed in a classroom and required to interact in pairs. Each pair was given one hour to complete the task assignment. After they completed the task assignment, they were given questionnaires.

Participants in the synchronous CMC group had to attend four experimental sessions conducted once a week over a four-week period. Participants were separated from their partners and placed in two different computer laboratories. The subjects in the synchronous CMC group interacted with their partners using Yahoo Messenger 9.0. Each session was scheduled for three hours to provide ample time for the participants to complete the task assignment. Once they finished the task assignment, they were given questionnaires. Then, they were told the date, time and venue for the next session.

The participants in the asynchronous CMC group also participated in four task assignments. Participants in this group received instructions and task assignment through e-mail. They were given five days for each task assignment. Immediately after the due date, they would receive questionnaires and were told to complete them within two days. The completed questionnaire was to be returned to the researcher as an attachment file. After they sent the completed questionnaire to the researcher; they received the next task assignment via e-mail. Walther and Burgoon (1992) used the same procedures.

\subsection{Participants}

A total of 140 undergraduate students from one large public university in Asia participated in this experiment. The experiment required zero-history partners, so participants were drawn mainly from two schools: the School of Communications and the School of Mathematics to ensure that no participants knew their partners before the experiment. Each participant was also asked whether they knew their partners before the experiment, and no one said yes.

Several announcements made during class hours invited students to participate in the experiment. Students who volunteered were asked to attend a short briefing prior to the experiment. A short briefing was conducted for communication students in a classroom at the School of Communication's building. Another briefing was conducted at the School of Mathematics for their partners. During the briefing, participants were given detailed information about the experiment. Students were told that participation in all four experimental sessions was important for getting full course credit. This requirement was imposed to reduce non-participation. Participants were told they would be interacting in pairs and would remain with the same partners throughout the four sessions. They were reminded not to make any outside contacts with their partners, except those held in the experimental sessions. The participants were informed that the experiment was to understand the communication process across media. The real objective of the study was withheld from the participants until the fourth session to prevent biasing the results. 
The random assignment of subjects involved two steps. First, subjects were randomly assigned to face-to-face control groups (50 students), synchronous CMC groups (50 students) and asynchronous CMC groups (40 students). Within each group, they were randomly assigned based on intracultural and intercultural conditions. The intracultural condition in the face-to-face group consisted of 28 participants, and the intercultural condition had 26 participants. In the synchronous group, 26 participants were assigned to the intracultural group, and another 24 participants were assigned to the intercultural group. Equal numbers of participants were assigned to the two conditions in the asynchronous CMC group, with 20 participants each. Participants in the intracultural condition interacted with partners of the same ethnic group, whereas those in the intercultural condition communicated with partners belonging to a different ethnic group.

The participants' ages ranged between 19-22 years, and the mean for the entire sample was 21 years $(\mathrm{SD}=1.23)$. The majority of the participants (80\%) were female, and only $20(20 \%)$ were male. In terms of race, almost half of the participants (48\%) were Malays, and 41 students (41\%) were Chinese. Only 11 students (11\%) were Indian and other minority ethnic groups.

\subsection{Task Assignment}

Subjects underwent four different task assignments throughout the four sessions. For each task assignment, they were given five questions to discuss with their partners. The questions were adapted from Ramirez and Burgoon (2001). All questions in the task assignments were personal in nature to encourage participants to disclose more information about themselves. Examples of the questions include the following: what do you like most about yourself and what are the worst things that have ever happened to you?

It should be noted that, this experiment used an informal type of social discussion as the task assignment. Other experiments on CMC (Walther \& Burgoon, 1992; Walther, 1994; Chidambaram, 1996) used decision-making task assignment, in which participants were given several organizational related problems and were required to make group decision to solve the problems. This kind of task assignment was mostly used in experiment attempting to understand the development of interpersonal relationship in groups or organizational settings.

In contrast, the present study was aimed to understand the development of interpersonal relationships among dyads in an informal setting. As the present study used MSN Messenger, an informal type of electronic chatting, the use of an informal type of task assignment, was deemed appropriate.

\subsection{Dependent Measures}

The dependent measure of interpersonal relationships was a combination of several measuring instruments by Parks and Floyd (1996), Burgoon and Hale (1987) and Ramirez and Burgoon (2001). The instrument asked respondents to report judgments about interpersonal relationships based on ten dimensions, i.e. breadth and depth (Parks \& Floyd, 1996); immediacy/affection; similarity; composure/relaxation; receptivity/trust; informality; equality and task/social orientation (Burgoon \& Hale, 1987); and perceived understanding (2As relationships develop, these dimensions should progress positively. The measurement of interpersonal relationships was based on a scale of 1 to 7 , with 1 indicating strongly disagree and 7 indicating strongly agree. The scale is reliable, with an alpha value of 0.89 .

Seven attitudinal items, composed of cognitive, affective and behavioral components, were developed to measure prejudice. Participants in the intercultural condition were asked to indicate their attitudes towards their intercultural session partners. Participants in the intracultural condition were asked to indicate their attitudes towards any ethnic group in the country, where the study took place. The response format included seven options running from strongly disagree and strongly agree. Exploratory factor analysis showed that all items belonged to one factor. Three items were removed because they had low reliability values. The final items for prejudice consisted of four items such as ("I frequently have a negative perception towards other cultures," and "Most people from other ethnic group cannot be trusted") with a reliability value of 0.78 . The four items accounted for 56.9 percent of the variance.

Ethnocentrism was measured with eight items partially adopted from Stephan and Stephan (1992) and had several adjustments in language and sentence structure, as the scale was primarily developed to be used among Americans. The response format was a seven-point, Likert-type scale. Exploratory factor analysis showed that all items belonged to one factor. Two items were removed because they had low reliability values. The final items for ethnocentrism consisted of four items such as ("My culture is superior to the other culture") with a reliability value of 0.84 . The remaining six items accounted for 61.4 percent of the variance. 


\section{Results and Discussion}

Figure 1 provides a graphical representation of the development of interpersonal relationships and the level of prejudice and ethnocentrism among intracultural and intercultural partners in the face-to-face group over time. The graph clearly demonstrates that a wide difference exists between intracultural and intercultural partners, with intracultural partners exhibited more developed interpersonal relationships as compared to cross-cultural partners in face-to-face group. The levels of prejudice and ethnocentrism were found to be lower among partners in intercultural conditions compared to those in the intracultural condition.

Figure 2 displays relational development, prejudice and ethnocentrism levels in the synchronous CMC group. The graph shows that the relational progression for both intracultural and intercultural relationship types was approximately similar. The level of prejudice and ethnocentrism for both groups tended to decrease as the relationship progressed.

Figure 3 displays relational development, prejudice and ethnocentrism levels in the asynchronous CMC group. Similar to the face-to-face group, some mean differences can be observed between the intracultural and the intercultural groups in the asynchronous CMC group, where the intracultural partners exhibited higher level of relational progression. The intercultural partners, however, displayed a much lower level of prejudice and ethnocentrism, compared to those in the intracultural condition.

Table 1 further provides a descriptive analysis of interpersonal relationships, level of prejudice and ethnocentrism over the four meeting times of the face-to-face and both $\mathrm{CMC}$ groups.

Table 2 presents mean scores of the dimensions of interpersonal relationships across relationship types and channel conditions. The intracultural partners in both face-to-face and asynchronous CMC showed to score higher in all relational dimensions compared to their counterparts in intercultural condition. The opposite is observed in the synchronous $\mathrm{CMC}$, with intercultural partners showed greater progression in seven out of ten relational dimensions compared to their counterparts in intracultural condition.

Hypotheses 1 and 2 were assessed with a mixed between-within subject repeated measures ANOVA. Preliminary checks ensured that there was no violation of the assumptions of normality, linearity, homogeneity of variances, homogeneity of regression slopes or reliable measurement of all variables. The relationship types (intracultural verses intercultural) were the between-group factor, while time was the within-subjects (Time 1, Time 2, Time 3 and Time 4), and the dependent variable was interpersonal relationships. In the face-to-face group, results indicated a significant main effect of relationship types $[F(1,50)=15.66, p<0.05$, Partial Eta Squared $=0.24]$. Using the guidelines proposed by Cohen (1988) $(0.01=$ small effect, $0.06=$ moderate effect, $0.14=$ large effect), this result suggests a very large effect size. Overall, intracultural partners $(M=5.66)$ showed greater relational progression than that of those in intercultural condition $(\mathrm{M}=5.16)$ in the face-to-face group. The analysis also detected no significant effect of time $[F(3,48)=0.29, \mathrm{p}>0.05$, Partial Eta Squared $=0.02]$ and no significant interaction effect between time and relationship types $[\mathrm{F}(3,48)=0.46, \mathrm{p}>0.05$, Partial Eta Squared $=0.03]$.

For the synchronous CMC group, the results show that the main effect of the relationship types was not significant, $[F(1,46)=0.36, p>0.05$, Partial Eta Squared 0.01]; no significant main effect of time $[F(3,44)=3.68, p>0.05$, Partial Eta Squared 0.05]; and, again, no significant interaction effect between relationship types and time $[F(3,44)=1.59, \mathrm{p}>0.05$, Partial Eta Squared 0.10].

For the asynchronous CMC group, the results demonstrate a significant main effect of relationship types, $[F(1,38)=4.69, p<0.05$, Partial Eta Squared 0.11]; no significant main effect of time $[F(3,36)=0.57, p>0.05$, Partial Eta Squared 0.06]; and no significant interaction effect between relationship types and time $[F(3,34)=0.10$, $p>0.05$, Partial Eta Squared 0.01]. Based on the mean value, the intracultural partner $(M=4.87)$ exhibited greater relational development than those in the intercultural condition $(\mathrm{M}=4.58)$ in the asynchronous CMC group.

To understand the effect of prejudice and ethnocentrism on relationship development among intracultural versus intercultural partners in face-to-face, synchronous CMC and asynchronous CMC settings as outlined in RQ1, a Pearson correlation analysis was conducted by collapsing data in all channel conditions. The results exhibited a significant negative correlation between prejudice and interpersonal relationship $(\mathrm{r}=-0.12, \mathrm{p}<0.01)$ and between ethnocentrism and interpersonal relationship $(\mathrm{r}=-0.31, \mathrm{p}<0.01)$. A significant positive correlation was found between prejudice and ethnocentrism $(\mathrm{r}=0.71, \mathrm{p}<0.01)$. See Table 3 .

From the Pearson correlation result, prejudice and ethnocentrism work in opposition to relational development. Thus, prejudice and ethnocentrism may act as confounding variables to relational development in all channel conditions. To confirm this assumption, we conducted a mixed between-within subjects repeated measures ANOVA with an analysis of covariance. The between-group factor was relationship types (intracultural verses 
intercultural); the within-subjects factor was time (Time 1, Time 2, Time 3 and Time 4); the dependent variable was interpersonal relationship; and the covariates were prejudice and ethnocentrism. After controlling for the effects of prejudice and ethnocentrism in the face-to-face group, the findings were similar to the earlier analysis. Results indicated a significant main effect for the relationship types $[F(1,48)=0.01, p<0.05$, Partial Eta Squared $=$ $0.16]$. Using guidelines proposed by Cohen (1988) $(0.01=$ small effect, $0.06=$ moderate effect, $0.14=$ large effect $)$, the results suggest a large effect size. The analysis also detected no significant main effect of time $[\mathrm{F}(3,46)=3.69$, $\mathrm{p}>0.05$, Partial Eta Squared $=0.07]$ and no significant interaction effect between time and relationship types $[\mathrm{F}(3,46)=2.46, \mathrm{p}>0.05$, Partial Eta Squared $=0.05]$. The results showed no significant effects of prejudice $[F(1,48)=1.64, p>0.05$, Partial Eta Squared $=0.03]$ and ethnocentrism $[F(1,48)=3.98, p>0.05$, Partial Eta Squared $=0.08]$ on the development of relationships in the face-to-face group.

After controlling for the effect of prejudice and ethnocentrism in the synchronous group, the results indicated no significant main effect of relationship types, $[F(1,46)=0.16, p>0.05$, Partial Eta Squared $=0.01]$. The analysis also detected no significant main effect of time, $[\mathrm{F}(3,44)=0.62, \mathrm{p}>0.05$, Partial Eta Squared $=0.04]$ and no significant interaction effect between time and relationship types $[\mathrm{F}(3,44)=1.88, \mathrm{p}>0.05$, Partial Eta Squared $=0.05]$. The results exhibited no significant effect of prejudice $[\mathrm{F}(1,46)=0.04, \mathrm{p}>0.05$, Partial Eta Squared $=0.01]$ and ethnocentrism $[F(1,46)=1.84, p>0.05$, Partial Eta Squared $=0.04]$ on the development of relationship in synchronous CMC group.

The opposite finding was observed in the asynchronous CMC group. After controlling for the effect of prejudice and ethnocentrism, the results indicated significant main effect of relationship types, $[F(1,36)=7.37, p<0.05$, Partial Eta Squared $=0.17]$. The analysis detected no significant main effect of time $[F(3,34)=0.89, p>0.05$, Partial Eta Squared $=0.7]$ and no significant interaction effect between time and relationship types $[\mathrm{F}(3,34)=0.06$, $p>0.05$, Partial Eta Squared $=0.01]$. The result exhibited no significant effect of prejudice $[F(1,36)=1.98, p>$ 0.05 , Partial Eta Squared $=0.05]$ and ethnocentrism $[F(1,36)=0.21, p>0.05$, Partial Eta Squared $=0.01]$ on the development of relationships in the asynchronous CMC group.

\section{Conclusion}

In conclusion, the results exhibited a significant main effect of relationship types (intracultural versus intercultural) on the development of interpersonal relationships in the face-to-face and asynchronous $\mathrm{CMC}$ groups, but not in the synchronous CMC group. In other words, both intracultural and intercultural communicative partners in the synchronous $\mathrm{CMC}$ group exhibited an almost similar rate of relational development across the four times. The face-to-face and the asynchronous CMC groups, in contrast, reported significant differences in relational progression, with the intracultural groups exhibiting significantly greater relational development when compared to the intercultural groups.

The findings provide a mixed support for the equalization view of $\mathrm{CMC}$, which claims that in absence of social context cues (such as physical environment, physical adornment and physical appearance) and social barriers (such as racial, race and status) in communication in CMC, communicators would show greater equalization in their interactions (Walther, 1992). More importantly, because the ethnicity of communicators was not apparent in $\mathrm{CMC}$, equal interactions among intracultural and intercultural partners occurred, which subsequently led to an approximately similar rate of relational progressions for both types of relationships.

Although the results for the face-to-face group are clear, it is important to consider how the results differ for the two CMC groups. Both intracultural and intercultural partners in the synchronous CMC group showed some similarity in relational progression over the four times. However, large differences were observed between the two groups in the asynchronous CMC.

The Principle of Interactivity (Burgoon, Bonito, Ramirez, Dunbar, Kam and Fischer, 2002) stresses that the differences among media are based on several criteria or structural affordances. The structural affordances include contingency (the ability to immediately respond to the next person); transformation (whether feedback and interdependence among actors is present); participation (whether the role of users is participative or observant); synchronicity (whether messages are exchanged in real time or are delayed); proximity (the geographical location of users), mediation (whether communication is mediated or not); parallelism (whether the format permits concurrent communication); and richness (whether non-verbal cues are accessible).

Based on these criteria, there should be large differences between synchronous CMC and asynchronous CMC, which are different based on contingency (the ability to immediately respond to the next person), synchronicity (whether messages are exchanged in real time or are delayed) and parallelism (whether the format permits concurrent communication). Walther (1994) conducted a longitudinal experiment investigating the effect of asynchronous and synchronous $\mathrm{CMC}$ on relational communication in CMC. The findings showed that differences 
existed between the asynchronous CMC compared to the two synchronous channels (synchronous CMC and face-to-face). Even though the statistical differences between asynchronous and synchronous CMC were not found to be significant, the mean comparison analysis between those channels showed that some differences exist between asynchronous and synchronous CMC.

The study findings confirmed that differences in channel synchrony produce differences in interpersonal effect among intracultural and intercultural communicative partners. Due to the high interactivity in synchronous CMC, these relationships grew at a faster rate. The synchronous CMC group, with its obvious limitation in the number of cues that can be transmitted over the channel and its delayed feedback, showed a slow development of interpersonal relationships over time. This finding is consistent with a study by Kaushik, David, Kline and Oaks (2002), who concluded that high interactivity, which included synchronicity, in an online environment would facilitate collaboration toward common interaction goals. In contrast, McGrath (1990) pointed out that the response lags, in combination with the loss of nonverbal cues in asynchronous CMC, might increase uncertainty and disrupt smooth interpersonal interactions. The lack of interactivity and response lags were shown to affect intercultural partners more than the intracultural partners in the asynchronous CMC group, causing major relational differences among them.

The study also showed no significant effect of prejudice and ethnocentrism on relational progression in the face-to-face and both CMC groups. In other words, both prejudice and ethnocentrism only exert minimal influence on relational development in the face-to-face group and CMC groups, as the amount of variance explained by the two confounding variables is small (less of $8 \%$ ). Clearly, the perceptual barriers do not play an important role in relational development in face-to-face and both CMC groups. The type of relationship proved to be the most significant factor in the development of interpersonal relationship, especially in the face-to-face group and asynchronous $\mathrm{CMC}$, with intracultural partners showing greater development in relational development compared to those in the intercultural condition.

This study has several limitations. The first is in the measurement procedure for the covariates. Prejudice and ethnocentrism were repeatedly measured after the experimental manipulation began. Therefore, the scores of the two covariates could be affected by the treatment condition. Future studies must include measurement of covariates prior to the treatment or experimental manipulations so that we can observe the mean differences between pre-test and post-test observations.

The second limitation is in the random assignment of subjects. In the study, subjects were randomly assigned to intercultural or intracultural conditions, without controlling for the gender of the subject. Thus, each pair could be either same-gender (male-male or female-female) or cross-gender (male-female). Future study should consider controlling for the type of relationships, either same-gender or cross-gender, in the treatment conditions, as the variable may exert considerable effect on the dependent variable.

The limitations notwithstanding, the results of the present study are particularly significant because they shed new light on the promising future for improved interethnic relationships in cyberspace, especially in synchronous CMC. The erosion of physical and cultural boundaries in cyberspace generally brings people of different ethnic groups virtually closer. With the limited number of research on intercultural relationship in cyberspace, the results of the study are particularly significant especially in many multi-ethnic, multi-cultural countries like Malaysia which past intercultural relations among major ethnic groups (Malay, Chinese and Indian) has been quite distant and aloof. In fact, the greatest threat to the country's stability, has been inter-ethnic disintegration.

Clearly from the study, increasing greater intercultural face-to-face contact does not help much in the development of trust, intimacy, similarity, depth and other dimensions of relationship. This finding poses question on the effectiveness on various intercultural programs and interventions conducted to foster better intercultural unity among various ethnic groups. Millions of money is thus spent for results that may be ineffective and uncertain.

On the other hand, online media especially chatting and instant messaging seemed to hold a better future in terms of interethnic integration since results of the study exhibited a more developed online relationship among intercultural partners with greater progression of immediacy/affection, trust, composure/relaxation, informality, equality and perceived understanding compared to their counterparts in the face-to-face group. In view of the findings, governmental agencies and non-governmental agencies may spend more efforts and time in developing online programs to inculcate greater online interaction and communication among people of different ethnic groups. Social and environmental-oriented projects that inculcate continuous or long term intercultural contact and interaction through the use of various online media such as Facebook, Instant Messaging and blog should be developed and enhanced to foster greater understanding and unity among people of different ethnicity. 
As recommended by one of the reviewers of this paper, future study should examine the effect of intercultural contact on relational progression in real life setting such online learning or distance learning environment using field experiment or survey. Many online learning programs in many universities require their students to work in pairs or groups with members of different cultures and ethnicities. This "real" online environment provides opportunity for the intercultural researchers to further test and verify the "equalization" view of CMC in a real-world setting. While lab experiment is often associated with artificiality and low generalizability, conducting similar study in a real-world setting would enable us to replicate the current study in a different setting.

In addition to cultural factor that may affect interpersonal development in an online setting, future study also needs to take into account or probably control the effect of other factors such as differences in religion, socio-economic status and educational background that may affect harmonious interaction between two or more people interacting. Similar to culture, these factors may be less salient in an online setting which may lead to a much better relational progression.

\section{References}

Allport, G. W. (1954). The Nature of Prejudice. Reading, MA: Addison-Wesley.

Altman, I. \& Taylor, D. (1973). Social Penetration: The Development of Interpersonal Relationships. New York: Holt, Rinehart \& Winston.

Amant, K. St. (2002). When cultures and computers collide: Rethinking computer-mediated communication according to international and intercultural communication expectation. Journal of Business and Technical Communication, 16, 196-214. http://dx.doi.org/10.1177/1050651902016002003

Amichai-Hamburger, Y. \& McKenna, K. Y. A. (2006). The Contact Hypothesis reconsidered: Interacting via the Internet. Journal of Computer-Mediated Communication, 11. [Online] Available: http://jcmc.indiana.edu/voll1/issue3/amichai-hamburger.html (March 10, 2011)

Barna, A. M. (1999). Stumbling Blocks in Intercultural Communication. In L. A. Samovar and R. E. Porter (eds) Intercultural Communication: A reader ( $8^{\text {th }}$ Ed.), (pp. 370-379). Belmont: Wadsworth Publishing Co.

Berger, C.R. (1988). Uncertainty and Information Exchange in Developing Relationships. In S. W. Duck (ed) Handbook of personal relationships, (pp. 239-252). Washington: John Wiley.

Bordia, P. (1997). Face-to-face verses computer-mediated communication: A synthesis of the experimental literature. The Journal of Business Communication, 34, 99-120. http://dx.doi.org/10.1177/002194369703400106

Burgoon, J. K. \& Hale, J. L. (1987). Validation and measurement of the fundamental themes of relational communication. Communication Monographs, 54, 19-41. http://dx.doi.org/10.1080/03637758709390214

Burgoon, J. K., Bonito, J. A., Ramirez, A., Dunbar, N. E., Kam, K. \& Fischer, J. (2002). Testing the Interactivity Principle: Effects of mediation, propinquity, and verbal and nonverbal modalities in interpersonal interaction. Journal of Communication, 52, 657-678.

Campbell, D.T. \& Stanley, J. C. (1963). Experimental and Quasi-Experimental Designs for Research. Chicago: Rand McNally College Publishing Company.

Chidambaram, L. (1996). Relational development in computer-supported groups. MIS Quarterly, 20, 143-163. http://dx.doi.org/10.2307/249476

Daft, R.L. \& Lengel, R.H. (1984). Information Richness: A New Approach to Managerial Behavior and Organizational Design. In B. M. Staw \& L.L. Cummings (eds), Research in organizational behavior 6, (pp. 191-233). Homewood, IL: JAI Publishing.

Dovidio, J. F., Esses, V. M., Beach, K. R. \& Gaertner, S. L. (2002). The Role of Affect in Determining Intergroup Behavior: The Case of Willingness to Engage in Intergroup Contact. In D. M. Mackie and E. R. Smith (eds) From prejudice to intergroup emotions: Differentiated reactions to social groups, (pp. 153-171). Philadelphia: Psychology Press.

Goldstein, S. B. \& Kim, R. I. (2005). Predictors of US college students' participation in study abroad programs: A longitudinal study. International Journal of Intercultural Relations, 30, 507-521. http://dx.doi.org/10.1016/j.jintrel.2005.10.001

Gudykunst, W. B. \& Kim, Y. Y. (1997). Communication With Strangers: An Approach to Intercultural Communication. New York: McGraw-Hill. 
Gudykunst, W. B. (1986). Ethnicity, Types of Relationship, and Intraethnic and Interethnic Uncertainty Reduction. In Y. Y. Kim (Ed), Interethnic Communication: Current research, (pp. 201-224). Newbury Park: Sage.

Harwood, J. (2010). The Contact Space: A novel framework for intergroup contact research. Journal of Language and Social Psychology, 29, 147-176. http://dx.doi.org/10.1177/0261927X09359520

Hiltz, S. R., Johnson, K. \& Turoff, M. (1986). Experiments in group decision-making: Communication process and outcome in face-to-face verses computerized conference. Human Communication Research, 13, 225-252. http://dx.doi.org/10.1111/j.1468-2958.1986.tb00104.x

Kaushik, R., David, P., Kline, S. \& Oaks, D. J. (2002). Social Presence Effects: A Study of CMC vs. FtF in collaborative fiction project. Paper presented in the Fifth Annual International Workshop, Presence 2002, Universidade Fernando Pessoa, Porto, Portugal, October 9-11, 2002.

Ma, R. (1996). Computer-Mediated Conversations as a New Dimension of Intercultural Communication Between East Asian and North American college students. In S. C. Herring (eds), Computer-mediated communication: Linguistic, social and cross cultural perspective, (pp.173-185). Philadelphia: John Benjamins Publishing Co.

McGrath, J. E. (1990). Time Matters in Groups. In J. Galegher, R. E. Kraut and C. Egido (eds), Intellectual teamwork: social and technical foundations of cooperative work, (pp. 23-61). Hillsdale, NJ: Lawrence Erlbaum.

McGuire, T.W., Kiesler, S. \& Siegel, J. (1987). Group and computer-mediated discussion effects in risk decision making. Journal of Personality and Social Psychology, 52, 917-930. http://dx.doi.org/10.1037/0022-3514.52.5.917

Mustafa, H. \& Hassan, M. S. (2006). Comparing intracultural and intercultural relationships in cyberspace. A quasi-longitudinal experimental study. Malaysian Journal of Language and Communication, 2, 23-37.

Neuliep, J. W. (2003). Intercultural Communication: A Contextual Approach (2nd ed). Boston: Houghton Mifflin Co.

Parks, M. R. \& Floyd, K. (1996). Making friends in cyberspace. Journal of Communication, 46, 80-97. http://dx.doi.org/10.1111/j.1460-2466.1996.tb01462.x

Ramirez, A. Jr. \& Burgoon, J.K. (2001). The Effect of Interactivity on Predicted Outcome Values 1: The Role of Richness and Mediation in Socially-Oriented Computer-Mediated Interactions. Paper presented in the Interpersonal Communication Division at the annual meeting of the National Communication Association, Atlanta, GA, November, 2001.

Rice, R.E. \& Love, G. (1987). Electronic emotion: Socioemotional content in a computer-mediated communication network. Communication Research, 14, 85-108. http://dx.doi.org/10.1177/009365087014001005

Rodino, M. (1997). Breaking out of binaries: Reconceptualizing gender and its relationships to language in computer-mediated communication. Journal of Computer-Mediated Communication, 3. [Online] Available http://jcmc.indiana.edu/vol3/issue3/rodino.html (January 5, 2003)

Siegel, J., Dubrovsky, V., Kiesler, S. \& McGuire, T. W. (1986). Group processes in computer-mediated communication. Organizational Behavior and Human Decision Processes, 37, 157-187. http://dx.doi.org/10.1016/0749-5978(86)90050-6

Simard, L. (1981). Cross-cultural interaction. Journal of Social Psychology, 113, 171-192. http://dx.doi.org/10.1080/00224545.1981.9924369

Stanback, M. \& Pearce, W. B. (1981). Talking to 'The Man’: Some communication strategies used by members of subordinate social groups. Quarterly Journal of Speech, 67, 21-30. http://dx.doi.org/10.1080/00335638109383548

Stephan, W. G. \& Stephan, C. W. (1992). Reducing intercultural anxiety through intercultural contact. International Journal of Intercultural Relations, 16, 96-106. http://dx.doi.org/10.1016/0147-1767(92)90007-H

Stephan, W. G. (1985). Intergroup Relation. In G. Lindzey and E. Aronson (eds), Handbook of social psychology, (pp. 599-658). MA: Addison-Wesley, Reading.

Stephan, W. G., Ageyev, V., Coates-Shrider, L., Stephan, C. W. \& Abalakina, M. (1994). On the relationship between stereotypes and prejudice: An international study. Personality and Social Psychology Bulletin, 20, 277-284. http://dx.doi.org/10.1177/0146167294203005 
Toal, M. C. \& McCroskey, J. C. (2001). Ethnocentrism and trait communication comprehension as predictors of interethnic communication apprehension and use of relational maintenance strategies in interethnic communication. Communication Quarterly, 49, 70-84. http://dx.doi.org/10.1080/01463370109385615

Turner, J. C. \& Giles, H. (1981). Intergroup Behavior. Chicago: University of Chicago Press.

Utz, S. (2000). Social Information Processing in MUDs: The development of friendships in virtual worlds. Journal of Online Behavior, 1. [Online] Available: http://www.behavior.net/JOB/v1n1/utz.html. (October 20, 2011)

Van Gelder, L. V. (1991). The Strange Case of the Electronic Lover. In C. Dunlop and R. Kling (eds), Computerization and controversy: Value conflicts and social choices, (pp. 364-375). Boston: Academic Press.

Varney, S.S. \& Cushner, K. (1990). Understanding cultural diversity can improve intercultural interactions. National Association of Secondary School Principals (NASSP) Bulletin, 74, 89-94.

Walther, J. B. \& Burgoon, J. K (1992). Relational communication in computer-mediated interaction. Human Communication Research, 19, 50-88. http://dx.doi.org/10.1111/j.1468-2958.1992.tb00295.x

Walther, J. B. (1992). Interpersonal effects in computer-mediated communication: A relational perspective. Communication Research, 19, 52-90. http://dx.doi.org/10.1177/009365092019001003

Walther, J. B. (1994). Anticipated ongoing interaction verses channel effects on relational communication in computer-mediated interaction. Human Communication Research, 2, 473-501. http://dx.doi.org/10.1111/j.1468-2958.1994.tb00332.x

Walther, J. B. (1996). Computer-mediated communication: Impersonal, interpersonal and hyperpersonal interaction. Communication Research, 23, 3-43. http://dx.doi.org/10.1177/009365096023001001

Walther, J. B. (2009). Computer-mediated communication and virtual groups: Applications to interethnic conflict. Journal of Applied Communication Research, 37, 225-238. http://dx.doi.org/10.1080/00909880903025937

Yum, Y. \& Hara, K. (2006). Computer-mediated relationship development: A cross-cultural comparison. Journal of Computer-Mediated Communication, 11, 133-152. http://dx.doi.org/10.1111/j.1083-6101.2006.tb00307.x

Table 1. Mean Scores of Interpersonal Relationships, Prejudice and Ethnocentrism among Intracultural and Intercultural Partners by Channels and Times

\begin{tabular}{|c|c|c|c|c|c|c|c|}
\hline Channel & $\begin{array}{l}\text { Relationship } \\
\text { Types }\end{array}$ & Mean Variables & Time 1 & Time 2 & Time 3 & Time 4 & Total \\
\hline \multirow[t]{6}{*}{ Face-to-face } & Intracultural & Interpersonal Relationship & 5.70 & 5.78 & 5.67 & 5.77 & 5.73 \\
\hline & group & Prejudice & 2.36 & 2.38 & 2.94 & 2.77 & 2.61 \\
\hline & & Ethnocentrism & 2.38 & 1.51 & 2.15 & 2.42 & 2.12 \\
\hline & Intercultural & Interpersonal Relationship & 5.05 & 5.14 & 5.10 & 5.20 & 5.12 \\
\hline & group & Prejudice & 1.51 & 1.66 & 2.17 & 2.00 & 1.84 \\
\hline & & Ethnocentrism & 2.00 & 1.89 & 1.99 & 1.69 & 1.89 \\
\hline \multirow{6}{*}{$\begin{array}{l}\text { Synchronous } \\
\text { CMC }\end{array}$} & Intracultural & Interpersonal Relationship & 5.29 & 5.36 & 5.43 & 5.54 & 5.40 \\
\hline & group & Prejudice & 2.13 & 1.93 & 2.19 & 1.83 & 2.02 \\
\hline & & Ethnocentrism & 2.31 & 1.90 & 1.84 & 1.62 & 1.92 \\
\hline & Intercultural & Interpersonal Relationship & 5.58 & 5.28 & 5.36 & 5.33 & 5.38 \\
\hline & group & Prejudice & 1.81 & 1.97 & 2.26 & 1.89 & 1.98 \\
\hline & & Ethnocentrism & 2.05 & 1.96 & 1.72 & 1.63 & 1.84 \\
\hline \multirow{6}{*}{$\begin{array}{l}\text { Asynchrono } \\
\text { us } \mathrm{CMC}\end{array}$} & Intracultural & Interpersonal Relationship & 4.71 & 4.94 & 4.81 & 5.02 & 4.87 \\
\hline & group & Prejudice & 2.60 & 2.53 & 2.64 & 2.48 & 2.56 \\
\hline & & Ethnocentrism & 2.84 & 3.05 & 3.12 & 3.13 & 3.04 \\
\hline & Intercultural & Interpersonal Relationship & 4.56 & 4.59 & 4.57 & 4.61 & 4.58 \\
\hline & group & Prejudice & 1.68 & 2.09 & 1.69 & 1.88 & 1.83 \\
\hline & & Ethnocentrism & 2.16 & 2.20 & 2.16 & 2.40 & 2.23 \\
\hline
\end{tabular}


Table 2. Mean Scores of Interpersonal Relationship Dimensions By Intercultural and Intracultural Partners Across Channels

\begin{tabular}{|l|c|c|c|c|c|c|}
\hline \multirow{2}{*}{$\begin{array}{c}\text { Dimension/ } \\
\begin{array}{c}\text { Relationship } \\
\text { Types }\end{array}\end{array}$} & \multicolumn{2}{|c|}{ Face-to-face } & \multicolumn{2}{c|}{ Synchronous CMC } & \multicolumn{2}{c|}{ Asynchronous CMC } \\
\cline { 2 - 7 } & $\begin{array}{c}\text { Intra } \\
\text { culture }\end{array}$ & $\begin{array}{c}\text { Inter } \\
\text { culture }\end{array}$ & $\begin{array}{c}\text { Intra } \\
\text { culture }\end{array}$ & $\begin{array}{c}\text { Inter } \\
\text { culture }\end{array}$ & $\begin{array}{c}\text { Intra } \\
\text { culture }\end{array}$ & $\begin{array}{c}\text { Inter } \\
\text { culture }\end{array}$ \\
\hline Breadth & $\mathbf{5 . 8 5}$ & 5.68 & $\mathbf{5 . 4 3}$ & 5.41 & $\mathbf{4 . 2 7}$ & 4.08 \\
\hline Depth & $\mathbf{5 . 1 9}$ & 4.84 & $\mathbf{5 . 0 4}$ & 4.73 & $\mathbf{4 . 2 6}$ & 3.83 \\
\hline $\begin{array}{l}\text { Immediacy/ } \\
\text { Affection }\end{array}$ & $\mathbf{5 . 7 8}$ & 5.49 & 5.67 & $\mathbf{5 . 7 3}$ & $\mathbf{5 . 2 0}$ & 4.67 \\
\hline Similarity & $\mathbf{4 . 9 0}$ & 4.71 & 4.60 & $\mathbf{4 . 6 2}$ & $\mathbf{4 . 6 8}$ & 3.74 \\
\hline Trust & $\mathbf{5 . 8 8}$ & 5.63 & 5.45 & $\mathbf{5 . 6 9}$ & $\mathbf{5 . 2 1}$ & 4.95 \\
\hline $\begin{array}{l}\text { Composure/ } \\
\text { Relaxation }\end{array}$ & $\mathbf{5 . 9 6}$ & 5.70 & 5.88 & $\mathbf{6 . 2 0}$ & $\mathbf{5 . 5 6}$ & 5.41 \\
\hline Informality & $\mathbf{5 . 6 4}$ & 5.45 & 5.41 & $\mathbf{5 . 5 4}$ & $\mathbf{4 . 9 2}$ & 4.66 \\
\hline Equality & $\mathbf{5 . 3 3}$ & 5.12 & 5.26 & $\mathbf{5 . 5 1}$ & $\mathbf{4 . 8 6}$ & 4.65 \\
\hline $\begin{array}{l}\text { Task/Social } \\
\text { Orientation }\end{array}$ & $\mathbf{4 . 2 5}$ & 4.00 & $\mathbf{4 . 2 0}$ & 3.70 & $\mathbf{3 . 6 7}$ & 3.36 \\
\hline $\begin{array}{l}\text { Perceived Under } \\
\text { standing }\end{array}$ & $\mathbf{5 . 8 9}$ & 5.51 & 5.68 & $\mathbf{5 . 8 8}$ & $\mathbf{5 . 3 5}$ & 5.27 \\
\hline
\end{tabular}

Table 3. Pearson Correlation Coefficient for Measured Variables

\begin{tabular}{|llccc|}
\hline Variables & & $\begin{array}{c}\text { Interpersonal } \\
\text { Relationship }\end{array}$ & Prejudice & Ethnocentrism \\
Interpersonal & Pearson $\mathrm{r}$ & 1 & $-0.12^{* *}$ & $-0.31^{* *}$ \\
Relationship & Sig $\mathrm{p}$ & & 0.000 & 0.000 \\
& & & & \\
Prejudice & Pearson $\mathrm{r}$ & & & $0.71^{* *}$ \\
& Sig $\mathrm{p}$ & & & 0.000 \\
Ethnocentrism & Pearson $\mathrm{r}$ & & & 1 \\
& Sig $\mathrm{p}$ & & & \\
\hline
\end{tabular}




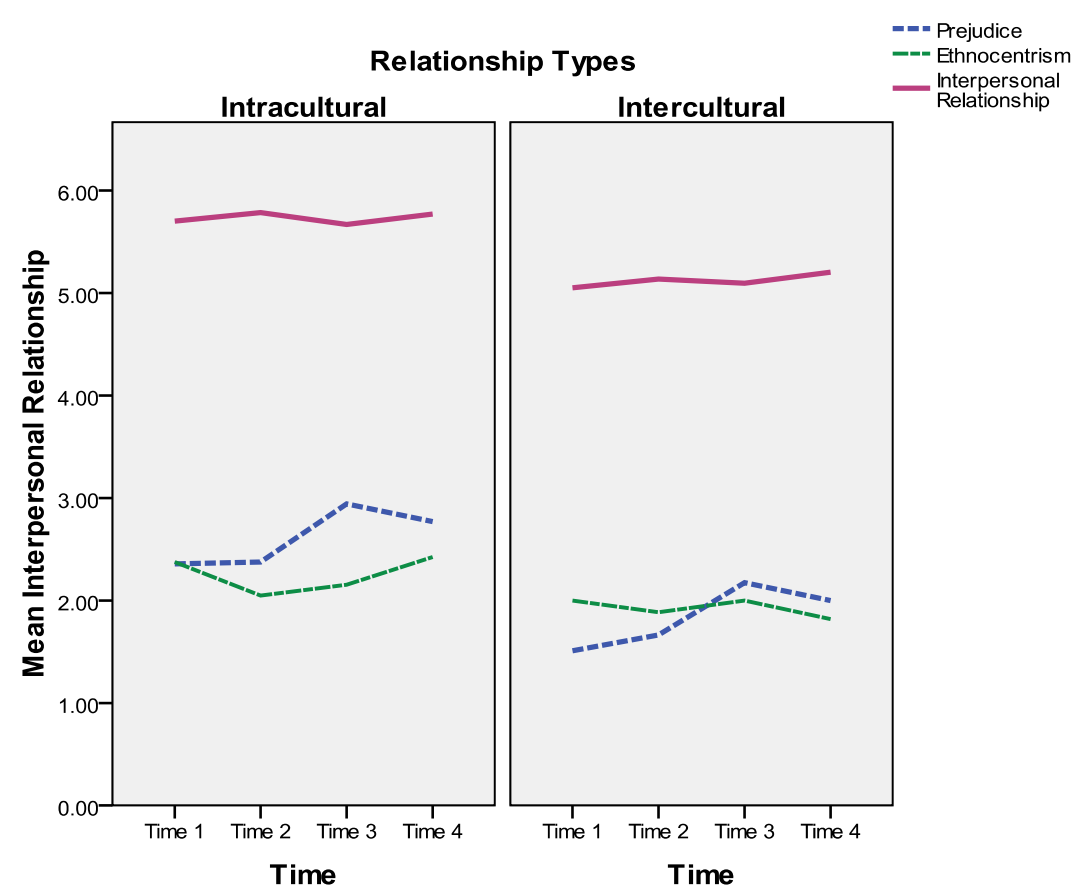

Figure 1. Relational Progression, Prejudice and Ethnocentrism Among Intracultural Versus Intercultural Partners in Face-to-Face Group

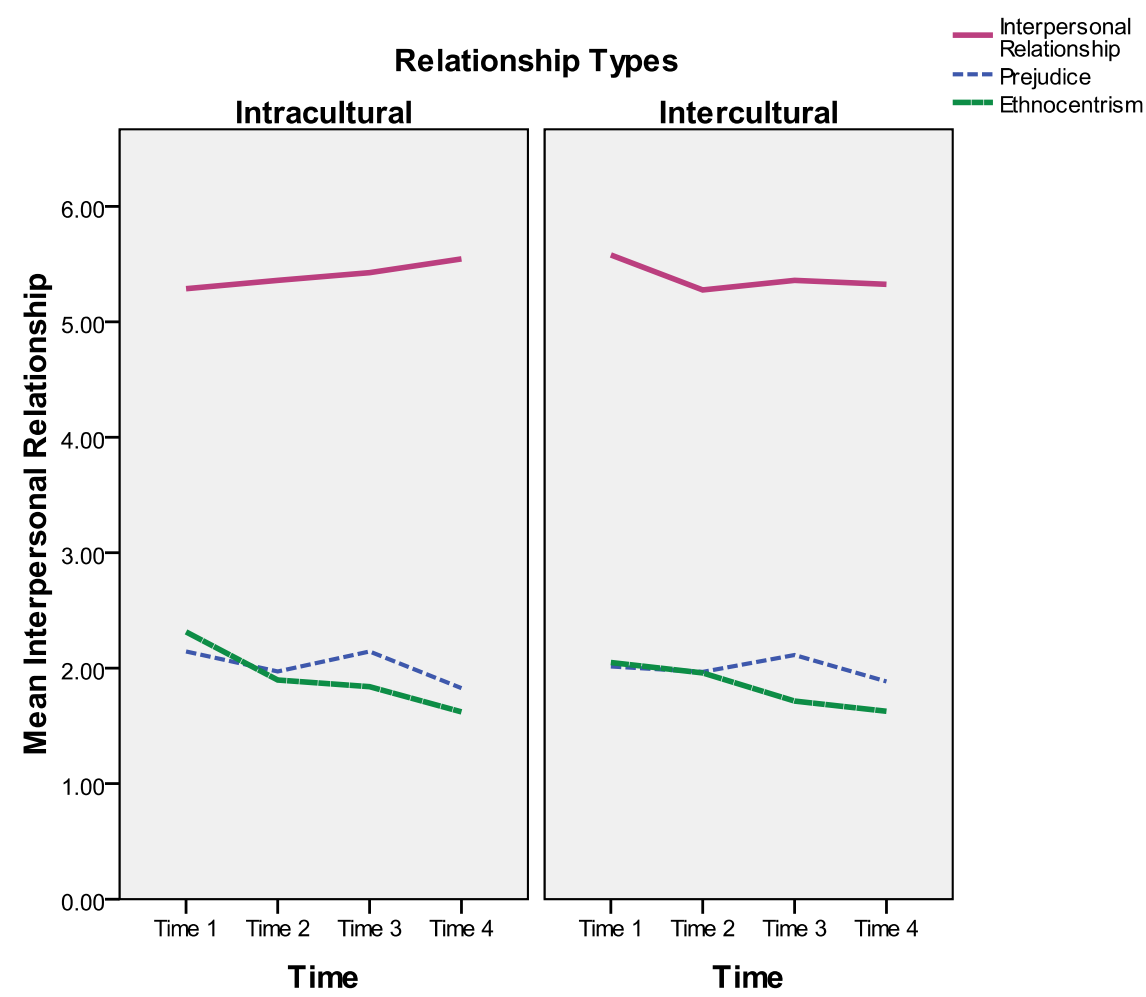

Figure 2. Relational Progression, Prejudice and Ethnocentrism Among Intracultural Versus Intercultural Partners in Synchronous CMC Group 


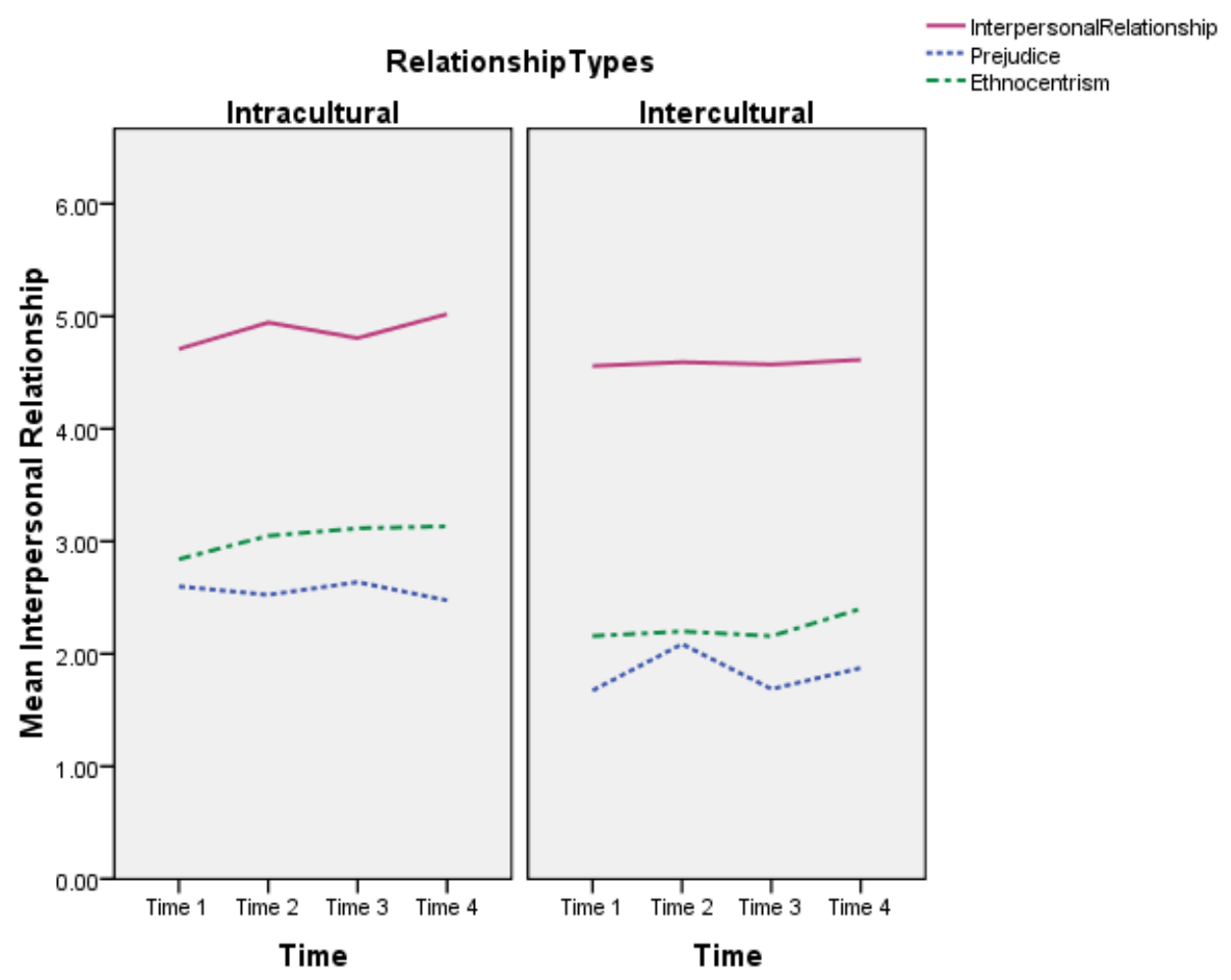

Figure 3. Relational Progression, Prejudice and Ethnocentrism Among Intracultural Versus Intercultural Partners in Asynchronous CMC Group 